\title{
ЭКОЛОГИЯ
}

DOI: https://doi.org/10.15688/jvolsu3.2018.1.14

UDC 330.15

LBC 65.28

\section{ASSESSMENT OF SOCIO-ECOLOGICAL-ECONOMIC PROCESSES TAKING INTO ACCOUNT THE TERRITORIAL SPECIFICS (THE CASE OF THE MOUNTAIN REGION)}

\author{
Oksana Z. Engoyan \\ Polzunov Altai State Technical University, Barnaul, Russian Federation \\ Andrey V. Stetsenko \\ Lomonosov Moscow State University, Moscow, Russian Federation
}

\begin{abstract}
The authors study the current problems of formalizing the mechanisms of nature management. A key issue is the development of the system of sustainable development indicators. This problem is recognized as relevant both internationally and nationally. The special attention is paid to the problem of taking into account the territorial specifics in the formalization of mechanisms for environmental and economic regulation. The indicators of sustainable development should, on the one hand, be comparable for different territories (but close in nature and climatic characteristics), and on the other hand, take into account the territorial specifics.

Among the elements of the formalization of mechanisms for environmental and economic regulation, the authors identify the economic capacity of the territory and the "feedback" effect between the natural complexes and the socio-economic system of the territory. The effect of this feedback is suggested by the authors to be called 'ecosystem reflection'. Ecosystemic reflection characterizes a complex of negative (depressing) and positive (stimulating) effects, manifested in the mechanism and socio-economic parameters of the ecosystem response to anthropogenic impact. The authors' research is based on historical experience, both large-scale precedents and local manifestations of ecosystem reflection.

As a large-scale example, the authors give an analysis of the socio-economic consequences of plowing steppe ecosystems (High Plains, USA). The results of this analysis show the mechanisms of ecosystem reflection and the characteristics of the economic capacity of the territory. As a local example, the authors give an analysis of changes in the high-mountain ecosystem (Kosh-Agachsky District, Altai Republic, Russia).

$\underset{\sigma}{\infty}$ These changes were caused by deforestation. As a result of anthropogenic impact, the natural and climatic

ㄱ conditions have changed. This led, respectively, to changes in the system and nature of environmental @ं management.

The authors propose a set of indicators for sustainable development as a tool for environmental and economic regulation. The authors use elements of matrix analysis to formalize separate mechanisms for regulating environmental and economic activity in the studied area.
\end{abstract}

Key words: economics of nature management, economic capacity of the territory, ecosystem reflection, m. mountainous areas, Altai. 
УДК 330.15

ББК 65.28

\title{
ОЦЕНКА СОСТОЯНИЯ \\ СОЦИО-ЭКОЛОГО-ЭКОНОМИЧЕСКИХ ПРОЦЕССОВ С УЧЕТОМ ТЕРРИТОРИАЛЬНОЙ СПЕЦИФИКИ (НА ПРИМЕРЕ ГОРНОГО РЕГИОНА)
}

\author{
Оксана Завеновна Енгоян \\ Алтайский государственный технический университет им. И.И. Ползунова, \\ г. Барнаул, Российская Федерация
}

\section{Андрей Владимирович Стеценко}

Московский государственный университет им. М.В. Ломоносова, г. Москва, Российская Федерация

Аннотация. Авторы статьи рассматривают актуальные проблемы формализации механизмов природопользования. Ключевая проблема - разработка системы показателей устойчивого развития. Эта проблема признана актуальной и на международном, и на национальном уровне. Особое внимание уделяется проблеме учета территориальной специфики при формализации механизмов эколого-экономического регулирования. Показатели устойчивого развития должны быть, с одной стороны, сопоставимы для различных территорий (но близких по природно-климатическим характеристикам), а с другой - учитывать территориальную специфику.

Среди элементов формализации механизмов эколого-экономического регулирования авторы выделяют хозяйственную емкость территории и эффект «обратной связи» между территориальными природными комплексами и социально-экономической системой территории. Эффект такой «обратной связи» авторы предлагают называть «экосистемной рефлексией». Экосистемная рефлексия характеризует комплекс отрицательных (угнетающих) и положительных (стимулирующих) эффектов, проявляющихся в механизме и социально-экономических параметрах ответной реакции - отклика экосистемы на антропогенное воздействие. Исследование авторов опирается на исторический опыт, как масштабных прецедентов, так и локальных проявлений экосистемной рефлексии.

В качестве масштабного примера авторы приводят анализ социально-экономических последствий распашки степных экосистем (Высокие Равнины, США). Результаты этого анализа показывают механизмы экосистемной рефлексии и характеристики хозяйственной емкости территории. В качестве локального примера авторы приводят анализ изменений в экосистеме высокогорья (Кош-Агачский район Республики Алтай, Россия). Эти изменения были вызваны сведением лесов. В результате антропогенного воздействия изменились природно-климатические условия. Это привело, соответственно, к изменениям в системе и характере природопользования.

В качестве инструментария эколого-экономического регулирования авторы предлагают комплекс показателей устойчивого развития. Авторы используют элементы матричного анализа для формализации отдельных механизмов регулирования эколого-экономической деятельности на исследуемой территории.

Ключевые слова: экономика природопользования, хозяйственная емкость территории, экосистемная рефлексия, горные территории, Алтай.

\section{Введение}

Современная динамика социально-экономических изменений неизбежно отражается на состоянии социоприродных комплексов, на ресурсах административно-территориальных образований. Экосистемы горных территорий в таких условиях подвергаются существенным рискам. В значительной сте- пени это связано с экологическими ограничениями, характерными для уязвимых природных территорий. Поэтому учет территориальной специфики при планировании и осуществлении проектов природопользования становится важным фактором управления регионом.

Данная проблема находит свое отражение в ключевых международных документах 
(«Повестка дня на XXI в.» (1992) и «Преобразование нашего мира: Повестка дня в области устойчивого развития на период до 2030 г.» (2015) [15; 17]).

В принятой в 1992 г. «Повестке дня на XXI в.» отмечалась необходимость правительствам и международным организациям совместно с частным сектором «разработать критерии и методологию оценки ресурсоемкости и экологического воздействия продуктов и процессов на протяжении всего их жизненного цикла» $[15$, п. 4.20]. Также подчеркивалось, что результаты таких оценок должны быть представлены в виде четких и ясных показателей, позволяющих адекватно информировать как потребителей, так и лиц, ответственных за принятие решений [15]. В то же время в документе отмечается необходимость «учесть системы ценностей, характерные для каждой конкретной страны, и возможность применения стандартов, которые действуют в большинстве развитых стран» [15, п. 6.39], однако при этом подчеркивается, что делать это нужно «без ущерба для таких критериев, которые могут быть согласованы международным сообществом, или для стандартов, которые необходимо будет установить на национальном уровне» [15].

В 2015 г. был принят документ, продолжающий эту логику и получивший название «Преобразование нашего мира: Повестка дня в области устойчивого развития на период до 2030 года» [17]. Документ констатирует необходимость применения системы глобальных показателей, которая «будет разработана Межучрежденческой и экспертной группой по показателям достижения целей в области устойчивого развития...». Кроме того, предусматривается, что «показатели будут дополняться показателями на региональном и национальном уровнях, которые будут разработаны государствами-членами, а также результатами проделанной работы по определению исходных значений для тех задач, по которым на национальном и глобальном уровнях исходные данные отсутствуют» [17, п. 83].

На национальном уровне также уделяется внимание вопросам экологически устойчивого развития. Так, среди поручений Президента России Правительству РФ (по итогам заседания Государственного совета по вопросу «Об экологическом развитии Российской Федерации в интересах будущих поколений», 27.12 2016 г. [7]) первым пунктом предписывается обратить особое внимание на использование системы индикаторов устойчивого развития, определение механизмов достижения целей и поэтапное решение задач экологически устойчивого развития территорий регионов на период до 2030 г. и на перспективу до 2050 г., а также на «учет влияния введения механизмов, обеспечивающих экологически устойчивое развитие, на деятельность хозяйствующих субъектов» [14].

В апреле 2017 г. вышел Указ Президента РФ от 19.042017 г. № 176 «О Стратегии экологической безопасности Российской Федерации на период до 2025 г.» [20, п. 9]. Среди основных механизмов реализации государственной политики в сфере обеспечения экологической безопасности документом предусматривается «разработка долгосрочных стратегий социально-экономического развития, предусматривающих... устойчивость экономики к изменению климата» $[20$, п. 27a].

Таким образом, формализация взаимосвязей между состояниями социально-экономической системы и социоприродного комплекса территории предполагает, во-первых, использование сопоставимых показателей, во-вторых, анализ динамики показателей, и, в-третьих, учет территориальной специфики, основанной на различиях экосистемных и культурно-исторических факторах, влияющих на хозяйственную деятельность на исследуемой территории.

В связи с этим при решении задач формирования механизма эколого-экономического регулирования хозяйственной деятельности на горных территориях важную роль играет, с одной стороны, хозяйственная емкость территории - ее экономико-территориальные характеристики соответствующих социоприродных комплексов, их потенциал и факторы, исторически обусловившие направление развития территории. А с другой - экосистемная рефлексия (отклик экосистемы на антропогенное воздействие с последующим отражением этого отклика на социально-экономических параметрах административно-территориального образования), отдельные элементы которой формализованы через показатели устойчивого развития.

Хозяйственная емкость территории характеризует возможности территориального 
природного комплекса устойчиво в средне- и долгосрочной перспективе воспроизводить определенный объем ресурсов и услуг, достаточный для организации и обеспечения в средне- и долгосрочной перспективе экономически эффективного и социально-экологически устойчивого развития территории. В таком понимании это понятие отличается от экологической емкости или биосферной емкости.

Поэтому при планировании хозяйственной деятельности и прогнозировании влияния форм и масштабов природопользования на горной территории, на наш взгляд, целесообразно опираться на понятие хозяйственной емкости территории, которое стоит дополнить понятием «экосистемная рефлексия» (комплекс отрицательных (угнетающих) и положительных (стимулирующих) эффектов, проявляющихся в механизме и социально-экономических параметрах ответной реакции, отклика $[2 ; 13 ; 22]$, экосистемы на антропогенное воздействие). Предлагаемый подход, на наш взгляд, позволяет, с одной стороны, выявить факторы, регулирующих хозяйственную деятельность на горных территориях, а с другой обосновать формирование такой территориальной экономической политики, которая позволяет увеличить хозяйственную емкость территории без ущерба для природных комплексов горных территорий. На этой основе может быть также проведен системный анализ программных документов с целью формирования нового взгляда на разграничение полномочий между федеральными и административно-территориальными управленческими структурами. Потребность в этом пересмотре возникла в связи с динамично меняющимися социально-экономическими условиями.

Природные комплексы способны восстанавливать свой ресурсный потенциал, однако этот процесс имеет сложную периодизацию: так, выращивание деловой древесины зависит от породы дерева и занимает порой десятилетия, тогда как злаковым достаточно одного теплого периода года; для накопления плодородного слоя требуются от нескольких лет до десятилетий, а для формирования углеводородов нужны тысячелетия. Учет периодов восстановления природных ресурсов напрямую зависит от интенсивности воздействия на природные комплексы, что, в свою очередь, определяется стратегией социально-экономического развития как территории, так и страны в целом. Подчеркнем: интенсивность воздействия на природные комплексы связана именно с хозяйственной емкостью территории, которая основывается на способности экосистем к воспроизводству социально и экономически значимых ресурсов.

В этой связи хозяйственная емкость территории является важным фактором устойчивого природопользования на горной территории.

И.В. Кузнецов, обобщая научное наследие В.И. Вернадского, писал: «Уже сейчас влияние человечества на природную среду становится в ряде отношений соизмеримым с тем, что совершается в природе под воздействием стихийных, вне человеческой деятельности лежащих, сил. Изменения эти столь значительны, что определенным образом сказываются на существовании того, что их породило, - на людях, создавших грандиозную систему общественного производства. Это следствие явно вступившего в действие неотвратимого закона обратной связи, имеющего силу везде, где есть развитие. Таким образом, социальная жизнь человечества все теснее сплетается в единую сеть взаимозависимостей с теми природными процессами и объектами, которые образуют первоисходную основу бытия. Сама эта первооснова становится существенно иной. На нее накладывается неизгладимый глубокий отпечаток человеческой деятельности, общественного труда, вооружаемого и многократно усиливаемого научной мыслью» [9, с. 461].

\section{Постановка проблемы}

Известно, что горные территории, обладая огромным экономическим потенциалом, играют стабилизирующую роль как в природно-климатических, так и в социально-экономических процессах. Поэтому изучение хозяйственной емкости территории с учетом экосистемной рефлексии приобретает особое значение при формировании территориальной экономической политики и выработке управленческих решений, эффективных как в краткосрочной, так и в долгосрочной перспективе. Кроме того, системный подход позволяет, с 
одной стороны, выявить факторы, ограничивающие хозяйственную деятельность на горных территориях, а с другой - обосновать формирование такой территориальной экономической политики, которая позволяет увеличить хозяйственную емкость территории без ущерба для природных комплексов горных территорий.

Однако понятие «хозяйственная емкость территории» не имеет устоявшегося определения, и различные авторы по-разному трактуют его смысл. Так, Н.Н. Лукьянчиков и И.М. Потравный отмечают, что «улучшение качества жизни населения должно обеспечиваться в пределах хозяйственной емкости экосистем, то есть экономическая деятельность не должна вызывать разрушения естественного механизма регуляции окружающей среды» $[12$, с. 73]. В то же время сегодня, как будет показано ниже, пределы хозяйственной емкости биосферы, не приводящие к разрушению естественного механизма регуляции окружающей среды и ее глобальным изменениям, игнорируются не только в силу эмпирической деформации социально-экономических систем, но и по причине отсутствия разработанной методики их определения и средне- и долгосрочного прогнозирования социально-экономических последствий - ответной реакции антропогенно измененной природной среды на хозяйственную деятельность в пределах конкретной экосистемы.

А согласно Н.Ф. Реймерсу, хозяйственная емкость территории - это возможность расширения хозяйственной деятельности на данной площади, как без крупных дополнительных затрат на ее благоустройство, главным образом путем интенсификации, комплексного использования освоенных ресурсов, так и с дополнительными капитальными затратами на обустройство и вовлечение в хозяйственное использование новых ресурсов (потенциальная емкость территории) [19, с. 123].

В то же время сегодня все чаще диагностируется факт, свидетельствующий о росте уровня и изменении качества самых различных рисков. В процессе активного индустриального строительства, осуществлявшегося в $\mathrm{XX}$ в., с одной стороны, были освоены наиболее удобные и доступные природные территории и ресурсы, а с другой - были накоплены определенные опыт и знания об ответной реакции - своеобразной рефлексии - природной среды на антропогенное воздействие.

Природно-ресурсная компонента - хозяйственная емкость территории - отмечалась многими исследователями. Например, Й. Тюнен свою конструкцию штандорта основывал на факторе почвы, А. Вебер особое значение придавал транспортным издержкам на доставку сырья (цит. по: [1]). Исследования В. Леонтьева уже в обязательном порядке учитывали ресурсную составляющую при составлении межотраслевого баланса [3; 10; 11]. Так, в работе «Межотраслевая экономика» (1997) Леонтьев отмечает, что «незримо присутствует... целая группа факторов, определяющих производственные возможности страны и в особенности ее сравнительные преимущества перед остальным миром, - это природные ресурсы: сельскохозяйственные угодья, леса, реки и крупные месторождения полезных ископаемых» [10, с. 78]. Масштабы, в рамках которых велись исследования группой В.В. Леонтьева, вынуждали его констатировать: «Отсутствие систематизированной количественной информации, подобной тем данным о капитале и трудовых ресурсах, которые были собраны, систематизированы и использованы в настоящей главе, пока не позволяет нам прямо ввести этот важный элемент в предварительный анализ» $[10$, с. 78$]$. В то же время на территориальном уровне подобная информация постепенно накапливается, систематизируется и уже сегодня позволяет использовать ее для первоначальной формализации оценок устойчивого развития и для научного обоснования разработки механизма эколого-экономического регулирования хозяйственной деятельности.

Алтайский регион - в первую очередь его горная часть - является экологическим донором для всего бассейна реки Обь, так как здесь располагаются не только запасы природных ресурсов в классическом понимании (минеральные и гидроэнергетические ресурсы, лесные массивы и пр.), но и верховья рек, обеспечивающих водой население обского бассейна, лесные массивы, играющие важную роль в климатических процессах, плодородные земли, являющиеся факторами (залогом) экологической, социальной, продовольствен- 
ной и в конечном счете экономической безопасности страны.

Обоснование хозяйственной емкости территории нуждается в исследованиях по двум основным направлениям: 1) анализ прецедентов природопользования на территориях, близких по природно-климатическим характеристикам; 2) выявление и учет специфических характеристик социоприродного комплекса, оказывающих существенное влияние на хозяйственную деятельность посредством механизма экосистемной рефлексии.

В истории природопользования накоплен значительный опыт ответной реакции антропогенно измененной среды обитания на социально-экономические процессы территориальных образований. Имеются как масштабные (опустынивание различных территорий в разные историческиепериоды; инвазионные виды растений и животных; и др.), так и локальные примеры (гидростроительство; вырубка лесов; и пр.).

Среди масштабных и наглядных примеров можно привести анализ данных по катастрофе 1931-1937 гг. на Высоких равнинах (США) [6; 21], который показывает предельно допустимую площадь пахотных земель на этой территории $-30 \%$. С аналогичной проблемой столкнулись и в нашей стране, причем не единожды. Так, В.В. Докучаев в своей работе «Наши степи прежде и теперь» (1892), анализируя природу и причины засух в России второй половины XIX в. и описывая негативные изменения, происходящие в степных экосистемax, называл в качестве основной причины сплошную распашку земель [4, с. 418]. При этом и Докучаев, и другие российские и советские ученые отмечали роль и народнохозяйственное значение формирования системы лесополос, а также участков с особым охранным режимом (своего рода экологического каркаса территории) не только для сохранения социоприродных комплексов, но и для повышения их продуктивности, что является прямым следствием хозяйственной емкости территории.

Среди локальных следует обратить внимание на имеющиеся исторические примеры антропогенного влияния на экосистемы территории, приведшие к изменениям в практике природопользования на территории Горного Алтая. Согласно свидетельствам исследова- телей середины XIX в., Кош-Агачский район (бассейн реки Чуя) Республики Алтай - «Это болотистая низменность, покрытая густым лесом (лиственником и тальником)... Густая зеленая трава здесь дает очень обильный корм для содержания скота, только по сырости местность эта очень нездорова и, кроме того, приспособлена насекомыми всякого рода...» [18, с. 142]. Однако уже в 1930-е гг. климат Кош-Агача характеризовался слабой влажностью воздуха [8, с. 419]. Одной из ключевых причин изменений в экосистеме высокогорий бассейна реки Чуя - правого крупнейшего притока р. Катунь - стали вырубки лесов: скорость сведения лесных массивов превышала скорость естественного лесовосстановления, что вкупе с фактором близости мерзлот, вероятно, стало критичным для социоприродного комплекса. На сегодняшний день территория Кош-Агачского района приравнена к территориям Крайнего Севера [16]. В этом контексте важное значение приобретает научное обоснование комплекса показателей устойчивого развития, учитывающих территориальную составляющую.

Согласно проведенным исследованиям [5], комплекс показателей устойчивого развития, предлагаемых для оценки динамики и трендов развития социоприродных систем горных территорий, включает два агрегированных индекса (ИСЧН - индекс скорректированных чистых накоплений; ИРЧП - индекс развития человеческого потенциала) и два упрощенных показателя (НC3 - нагрузка на сельскохозяйственные земли; ЭПД - электропотребление на душу населения). Для целей регулирования и определения вектора интегральной оценки предложенный комплекс рассмотрен в виде матрицы, элементами которой являются данные динамики соответствующих показателей (см. таблицу).

Соответственно, определитель матрицы характеризует вектор движения, исчисленный на основе показателей динамики элементов матрицы: отрицательный детерминант (понижательный тренд) свидетельствует о негативном состоянии показателей устойчивости, рассматриваемых за исследуемый период. Это показывает наличие рисков и снижение устойчивости социоприродного комплекса территории (см. рисунок). 
Матрица показателей оценки устойчивого развития социоприродных систем

\begin{tabular}{l|c|c}
\multicolumn{1}{c|}{ показатели } & агрегированные & упрощенные \\
\hline эколого-экономические & $\mathrm{T}_{\text {ИСчН }}$ & $\mathrm{T}_{\mathrm{HC}}$ \\
\hline социально-экономические & $\mathrm{T}_{\text {ИРчП }}$ & $\mathrm{T}_{\text {эпд }}$
\end{tabular}

Примечание. $\mathrm{T}_{\text {исчн }}$ - динамика изменений ИСЧН; $\mathrm{T}_{\text {ирчп }}-$ динамика изменений ИРЧП; $\mathrm{T}_{\text {нсз }}$ - динамика изменений НС3; Т эпд - динамика изменений ЭПД. Составлено авторами.

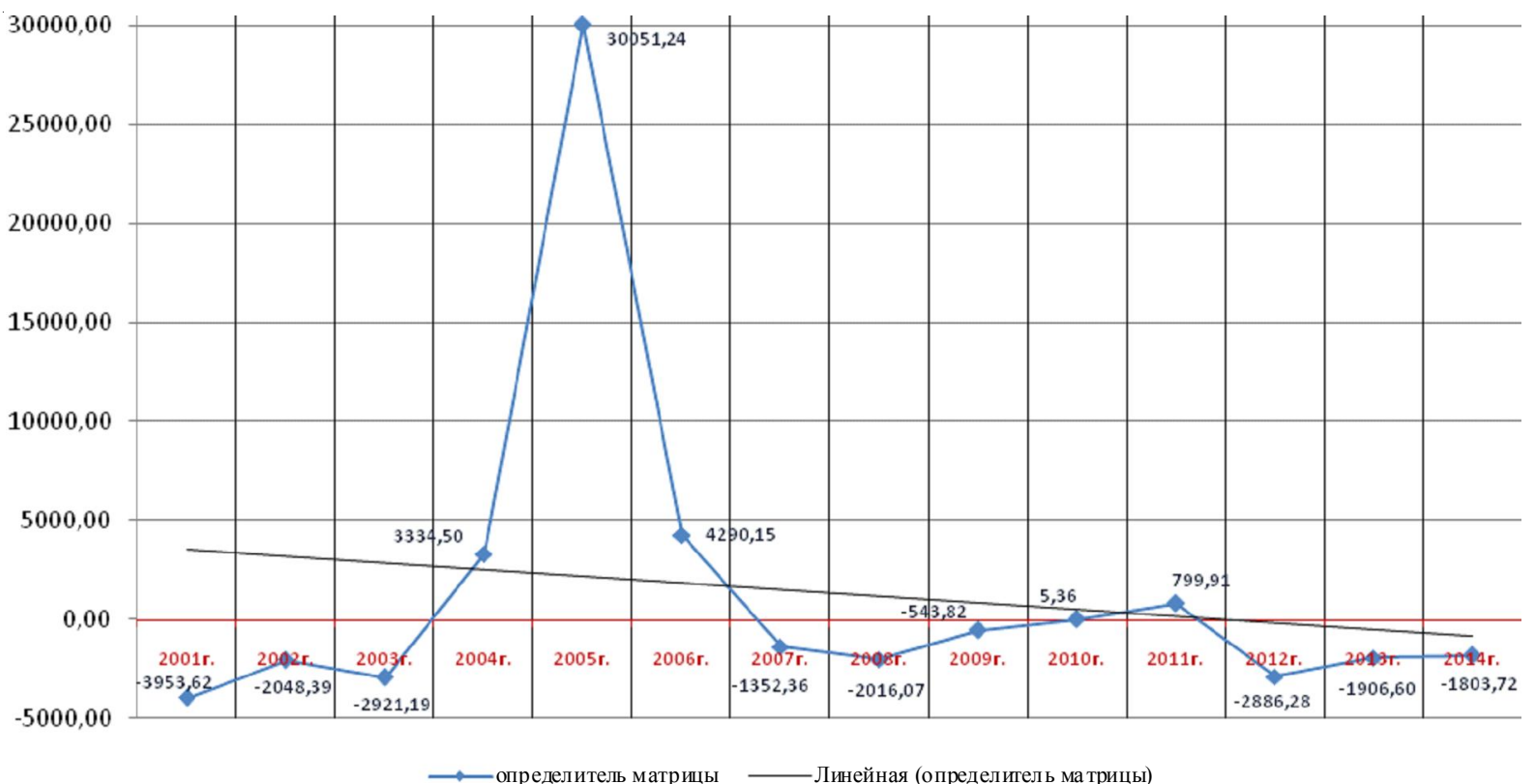

Рисунок. Динамика определителя матрицы, исчисленного по динамике показателей устойчивого развития Алтайского региона (ИСЧН, ИРЧП, ЭПД, НСЗ) за период 2001-2014 гг.

Примечание. Составлено на основе авторских расчетов.

Таким образом, можно говорить о формализации инструментария при формировании механизма эколого-экономического регулирования хозяйственной деятельности на горных территориях с учетом хозяйственной емкости территории и экосистемной рефлексии.

\section{Выводы}

На основании проведенного исследования нами выделены основные направления эколого-экономического регулирования хозяйственной деятельности на горных территориях: 1) предотвращение формирования трендов отрицательной экосистемной рефлексии; 2) внедрение технологий и способов организации и ведения хозяйственной деятельности, способствующих увеличению хозяйственной емкости территории; 3) выработка механизмов купирования рисков, связанных с фак- торами угнетения (давления на) конкурентоспособности отраслей и предприятий, развивающихся на горных территориях (так, и отечественный, и зарубежный опыт свидетельствует, что хозяйственная емкость территории может быть повышена за счет внедрения научно обоснованных методов оптимизации природопользования. Решительные меры - лесные полосы, искусственные водоемы, консервация пашни [23] - позволили не только остановить дигрессию на Высоких равнинах, но и в дальнейшем организовывать природопользование на предельном уровне тридцати процентов).

В целом же проведенный анализ комплекса показателей устойчивого развития для горной территории (на примере Республики Алтай) свидетельствует не только о понижательном тренде агрегированного показателя, но и о необходимости его включения в систе- 
му контрольных (прогнозных, плановых, целевых) показателей в программные документы. Следует подчеркнуть, что включение в программные документы перечня показателей устойчивого развития (прогнозных, плановых, целевых - в зависимости от статуса документа) позволит заложить основу для формирования механизмов эколого-экономического регулирования при организации и ведении хозяйственной деятельности на территории Горного Алтая.

\section{СПИСОК ЛИТЕРАТУРЫ}

1. Бияков, О. А. Теория экономического пространства: методологический и региональный аспекты / О. А. Бияков. - Томск : Изд-во Том. ун-та, 2004. $-152 \mathrm{c}$.

2. Бобылев, С. Н. Экономика природопользования / С. Н. Бобылев, А. Ш. Ходжаев. - М., 2003. $567 \mathrm{c}$.

3. Будущее мировой экономики : доклад / группа экспертов ООН во главе с В. Леонтьевым. М. : Междунар. отношения, 1979. - 216 c.

4. Докучаев, В. В. Избранные труды / В. В. Докучаев. - М. : Изд-во Академии наук СССР, 1949. $649 \mathrm{c}$.

5. Енгоян, О. 3. Территориальный фактор при формировании механизмов эколого-экономического регулирования на горных территориях / О. 3. Енгоян, А. В. Стеценко // Вестник Алтайского государственного аграрного университета. - 2017. - № 6. C. 101-106.

6. Енгоян, О. 3. Хозяйственная емкость территории и экосистемная рефлексия/ О. 3. Енгоян // Мир науки, культуры, образования. - 2014. № 3 (46). - C. 380-382.

7. Заседание Государственного совета по вопросу об экологическом развитии Российской Федерации в интересах будущих поколений. 27 дек. 2016 г. - Электрон. дан. - Режим доступа: http://kremlin.ru/events/president/news/53602. Загл. с экрана.

8. Кожарин, Ф. С. Проблема гибридизации яка / Ф. С. Кожарин // [Ойротия. Труды сессии СОПС по изучению производительных сил Ойротской автономной области]. - Л. : Изд-во Академии наук CCCP, 1937.- C. 417-433.

9. Кузнецов, И. В. Естествознание, философия и становление ноосферы / И. В. Кузнецов // Философские мысли натуралиста / В. И. Вернадский ; пред. ред. кол. А.Л. Яншин. - М. : Наука, 1988. - С. 460-480.

10. Леонтьев, В. В. Межотраслевая экономика : пер. с англ. / В. В. Леонтьев; [автор предисл. и науч. ред. А. Г. Гранберг]. - М. : Экономика, 1997. $479 \mathrm{c}$.

11. Леонтьев В.В. Экономические эссе. Теории, исследования, факты и политика : [пер. с англ.] / В. В. Леонтьев. - М. : Политиздат, 1990. - 415 с.

12. Лукьянчиков, Н. Н. Экономика и организация природопользования : учебник / Н. Н. Лукьянчиков, И. М. Потравный. - М. : ЮНИТИ-ДАНА, 2010. -687 c.

13. Мордвинов, В. И. Теория климата : учеб. пособие / [В. И. Мордвинов, И. В. Латышева, Е. В. Девятова]. - Иркутск : Изд-во ИГУ, 2013.$187 \mathrm{c}$.

14. Перечень поручений Президента РФ по итогам заседания Государственного совета по вопросу «Об экологическом развитии Российской Федерации в интересах будущих поколений», состоявшегося 27 декабря 2016 года. - Электрон. дан. 24 янв. 2017. - Режим доступа : http://kremlin.ru/acts/ assignments/orders/53775. - Загл. с экрана.

15. Повестка дня на XXI век : принята на Конференции ООН по окружающей среде и развитию, Рио-де-Жанейро, 3-14 июня 1992 г. - [510с.]. - Электрон. дан. - Режим доступа : http://www.un.org/ru/ documents/decl_conv/conventions/agenda21. - Загл. с экрана.

16. Постановление Совмина СССР от 03.01.1983 № 12 «О внесении изменений и дополнений в Перечень районов Крайнего Севера и местностей, приравненных к районам Крайнего Севера, утвержденный Постановлением Совета Министров СССР от 10 ноября 1967 г. № 1029» (вместе с «Перечнем районов Крайнего Севера и местностей, приравненных к районам Крайнего Севера, на которые распространяется действие Указов Президиума Верховного Совета СССР от 10 февраля 1960 г. и от 26 сентября 1967 г. о льготах для лиц, работающих в этих районах и местностях», утв. Постановлением Совмина СССР от 10.11.1967 № 1029) : (ред. от 03.03.2012). - Электрон. дан. - Режим доступа: http://www. consultant. $\mathrm{ru} /$ cons/cgi/online. cgi?req $=$ doc\&base $=\mathrm{LAW} \& \mathrm{n}=$ $127020 \& \mathrm{fld}=134 \& \mathrm{dst}=100060,0 \& \mathrm{rnd}=$ $0.23269559281341345 \# 06873561626920528$. - Загл. с экрана.

17. Преобразование нашего мира : Повестка дня в области устойчивого развития на период до 2030 г. - Электрон. дан. - Режим доступа : https:// documents-dds-ny.un.org/doc/UNDOC/GEN/N15/ 291/92/PDF/N1529192.pdf?OpenElement ; http:// www.un.org/sustainabledevelopment/ru/sustainabledevelopment-goals/. - Загл. с экрана.

18. Радлов, В. Ф. Торговые сношения России с Западной Монголией и их будущность / В. Ф. Радлов. - Санкт-Петербург, 1871. - (Записки Императорского Русского Географического общества по 
отделению статистики ; т. 2). - Цит. по: Путешествие по Алтаю. Горно-Алтайск : АУ РА Литературно-издательский дом «Алтын-Туу», 2011. 544 с. (Слово об Алтае; т. III, кн. 2).

19. Реймерс, Н. Ф. Природопользование : словарь-справочник / Н. Ф. Реймерс. - М. : Мысль, 1990. $-637 \mathrm{c}$.

20. Стратегия экологической безопасности Российской Федерации на период до 2025 г. : (утв. Указом Президента Российской Федерации от 19.042017 г. № 176). - Электрон. дан. - Режим доступа : http://www.kremlin.ru/acts/bank/41879. - Загл. с экрана.

21. Kasperson, J. X. Regions at risk: comparisons of threatened environments / J. X. Kasperson, R. E. Kasperson, B. L. Turner. - Electronic data. Tokyo ; New-York ; Paris : United Nations University Press, 1995. - Mode of access: http://archive.unu.edu/ unupress/unupbooks/uu14re/uu14re00.htm\#Contents.

22. Measuring Progress Towards Sustainability. A Treatise for Engineers / Subhas K. Sikdar, Debalina Sengupta, Rajib Mukherjee. - Switzerland : Springer International Publishing, 2017. - 290 p.

23. NRCS. - Electronic data. - Mode of access: http://www.nrcs.usda.gov/wps/portal/nrcs/detail/ national/about/history/?cid=nrcs143 021392 .

\section{REFERENCES}

1. Biyakov O.A. Teoriya ekonomicheskogo prostranstva: metodologicheskiy $i$ regionalnyy aspekty [Theory of Economic Space: Methodological and Regional Aspects]. Tomsk, Izd-vo Tom. un-ta, 2004. 152 p.

2. Bobylev S.N., Khodzhaev A.Sh. Ekonomika prirodopolzovaniya [Economics of Nature Management]. Moscow, 2003. 567 p.

3. Budushchee mirovoy ekonomiki: doklad / gruppa ekspertov OON vo glave s V. Leontyevym [The Future of the World Economy: Report / Group of Experts of the United Nations, Headed by V. Leontyev]. Moscow, Mezhdunar. otnosheniya Publ., 1979. 216 p.

4. Dokuchaev V.V. Izbrannye trudy [Selected Works]. Moscow, Izd-vo Akademii nauk SSSR, 1949. 649 p.

5. Engoyan O.Z., Stetsenko A.V. Territorialnyy faktor pri formirovanii mekhanizmov ekologoekonomicheskogo regulirovaniya na gornykh territoriyakh [Territorial Factor in the Formation of Mechanisms for Environmental and Economic Regulation in Mountain Areas]. Vestnik Altayskogo gosudarstvennogo agrarnogo universiteta, 2017, no. 6, pp. 101-106.

6. Engoyan O.Z. Khozyaystvennaya emkost territorii i ekosistemnaya refleksiya [Economic Capacity of the Territory and Ecosystem Reflection]. Mir nauki, kultury, obrazovaniya, 2014, no. 3 (46), pp. 380-382.

7. Zasedanie Gosudarstvennogo soveta po voprosu ob ekologicheskom razvitii Rossiyskoy Federatsii $v$ interesakh budushchikh pokoleniy. 27 dek. 2016 g. [Meeting of the State Council on the Issue of Environmental Development of the Russian Federation for the Benefit of Future Generations]. URL: http://kremlin.ru/events/president/news/53602.

8. Kozharin F.S. Problema gibridizatsii yaka [The Problem of Yak Hybridization]. Oyrotiya. Trudy sessii SOPS po izucheniyu proizvoditelnykh sil Oyrotskoy avtonomnoy oblasti. Leningrad, Izd-vo Akademii nauk SSSR, 1937, pp. 417-433.

9. Kuznetsov I.V. Estestvoznanie, filosofiya i stanovlenie noosfery [Natural Science, Philosophy and the Formation of Noosphere]. Vernadskiy V.I., ed. Filosofskie mysli naturalista [Philosophical Thoughts of the Naturalist]. Moscow, Nauka Publ., 1988, pp. 460-480.

10. Leontyev V.V. Mezhotraslevaya ekonomika [Interindustry Economics]. Moscow, Ekonomika Publ., 1997. 479 p.

11. Leontyev V.V. Ekonomicheskie esse. Teorii, issledovaniya, fakty i politika [Economic Essays. Theories, Studies, Facts and Politics]. Moscow, Politizdat Publ., 1990. 415 p.

12. Lukyanchikov N.N., Potravnyy I.M. Ekonomika i organizatsiya prirodopolzovaniya [Economics and Organization of Nature Management]. Moscow, YuNITI-DANA Publ., 2010. 687 p.

13. Mordvinov V.I., Latysheva I.V., Devyatova E.V. Teoriya klimata [Theory of Climate]. Irkutsk, Izd-vo IGU, 2013. $187 \mathrm{p}$.

14. Perechen porucheniy Prezidenta RF po itogam zasedaniya Gosudarstvennogo soveta po voprosu «Ob ekologicheskom razvitii Rossiyskoy Federatsii v interesakh budushchikh pokoleniy", sostoyavshegosya 27 dekabrya 2016 goda [List of Instructions of the President of the Russian Federation on the Results of the Meeting of the State Council "On the Ecological Development of the Russian Federation for the Benefit ofFuture Generations", Held on December 27, 2016]. URL: $\mathrm{http}: / / \mathrm{kremlin} . \mathrm{ru} / \mathrm{acts} /$ assignments/orders/53775.

15. Povestka dnya na XXI vek: prinyata na Konferentsii OON po okruzhayushchey srede $i$ razvitiyu, Rio-de-Zhaneyro, 3-14 iyunya $1992 \mathrm{~g}$. [Agenda for the $21^{\text {st }}$ Century: Adopted by the United Nations Conference on Environment and Development, Rio de Janeiro, 3-14 June 1992]. Rio de Janeiro, 1992. 510 p. URL: http://www.un.org/ru/documents/ decl_conv/conventions/agenda21.

16. Postanovlenie Sovmina SSSR ot 03.01.1983 № 12 «O vnesenii izmeneniy $i$ dopolneniy v Perechen rayonov Kraynego Severa $i$ mestnostey, priravnennykh $k$ rayonam Kraynego Severa, utverzhdennyy Postanovleniem Soveta Ministrov 
SSSR ot 10 noyabrya 1967 g. № 1029» (vmeste s «Perechnem rayonov Kraynego Severa i mestnostey, priravnennykh $k$ rayonam Kraynego Severa, na kotorye rasprostranyaetsya deystvie Ukazov Prezidiuma Verkhovnogo Soveta SSSR ot 10 fevralya 1960 g. $i$ ot 26 sentyabrya 1967 g. o lgotakh dlya lits, rabotayushchikh $v$ etikh rayonakh $i$ mestnostyakh», utv. Postanovleniem Sovmina SSSR ot 10.11.1967 № 1029): (red. ot 03.03.2012). [Decree of the Soviet Ministry of the USSR of January 3, 1983 no. 12 "On Amendments and Additions to the List of the Regions of the Far North and Territories Having Equal Status with the Regions of the Far North, Approved by Decree of the Council of Ministers of the USSR of November 10, 1967 no. 1029" (along with "The List of the Regions of the Far North and Territories Having Equal Status with the Regions of the Far North, which Fall under the Orders of Presidium of the Supreme Council of the USSR of February 10, 1960 and of September 26, 1967 on Benefits for People Working in These Regions and Territories", Approved by Decree of the Soviet Ministry of the USSR on November 10, 1967 no. 1029]. URL: http://www. consultant.ru/cons/cgi/online.cgi?req $=$ doc\&base $=\mathrm{LAW} \& \mathrm{n}=127020 \& \mathrm{fld}=134 \& \mathrm{dst}=100060,0$ \&rnd $=0.23269559281341345 \# 06873561626920528$.

17. Preobrazovanie nashego mira: Povestka dnya $v$ oblasti ustoychivogo razvitiya na period do $2030 \mathrm{~g}$. [Transformation of Our World: Agenda in the Sphere of Sustainable Development for the Period up to 2030]. URL: http:// www.un.org/sustainabledevelopment/ru/ sustainable-development-goals/.
18. Radlov V.F. Torgovye snosheniya Rossii s Zapadnoy Mongoliey i ikh budushchnost [Trade Relations of Russia and Western Mongolia and Their Future]. Saint Petersburg, 1871. (Notes of the Russian Imperial Geographic Community at the Department of Statistics; vol. 2). Cit. ex: Journey across Altai. GornoAltaysk, Altyn-Tuu Publ., 2011. 544 p. (A Word on Altai; vol. III, book 2).

19. Reymers N.F. Prirodopolzovanie: slovarspravochnik [Nature Management: DictionaryReference Book]. Moscow, Mysl Publ., 1990. $637 \mathrm{p}$.

20. Strategiya ekologicheskoy bezopasnosti Rossiyskoy Federatsii na period do 2025 g.: (utv. Ukazom Prezidenta Rossiyskoy Federatsii ot 19.042017 g. № 176) [The Strategy of Ecological Security in the Russian Federation until 2025 (Approved by Presidential Decree of the Russian Federation on April 19, 2017 no. 176]. URL: http:// www.kremlin.ru/acts/bank/41879.

21. Kasperson J.X., Kasperson R.E., Turner B.L. Regions at risk: comparisons of threatened environments. Tokyo; New-York; Paris, United Nations University Press, 1995. URL: http://archive.unu.edu/ unupress/unupbooks/uu14re/uu14re00.htm\#Contents.

22. Subhas K. Sikdar, Debalina Sengupta, Rajib Mukherjee. Measuring Progress Towards Sustainability. A Treatise for Engineers. Switzerland, Springer International Publishing, 2017. 290 p.

23. NRCS. URL: http://www.nrcs.usda.gov/wps/ portal $/ \mathrm{nrcs} / \mathrm{detail} / \mathrm{national} /$ about $/$ history $/$ ?cid= nrcs143_021392.

\section{Information about the Authors}

Oksana Z. Engoyan, Researcher, International Department of UNESCO (Ecological Education in Siberia), Polzunov Altai State Technical University, Prosp. Lenina, 46, 656038 Barnaul, Russian Federation, engoyan.oz@yandex.ru.

Andrey V. Stetsenko, Candidate of Sciences (Economics), Researcher, Department of Economics of Nature Management, Lomonosov Moscow State University, Leninskie gory, 1, bld. 46, 119991 Moscow, Russian Federation, astetsenko@mail.ru.

\section{Информация об авторах}

Оксана Завеновна Енгоян, научный сотрудник, международная кафедра ЮНЕСКО «Экологическое образование в Сибири», Алтайский государственный технический университет им. И.И. Ползунова, просп. Ленина, 46, 656038 г. Барнаул, Российская Федерация, engoyan.oz@yandex.ru.

Андрей Владимирович Стеценко, кандидат экономических наук, научный сотрудник кафедры экономики природопользования, Московский государственный университет им. М.В. Ломоносова, Ленинские горы, 1, стр. 46, 119991 г. Москва, Российская Федерация, astetsenko@mail.ru. 